\title{
Population Aging, Human Capital Accumulation, and Productivity Growth
}

\author{
Edited by \\ Alexia Prskawetz, David E. Bloom, and Wolfgang Lutz \\ Published by the Population Council, New York, NY, \\ as a Supplement to Volume 34 (2008) Population and Development Review
}

ISBN: 978-0-87834-116-0

Price: $\$ 25.00,326$ pages.

\author{
Herbert C. Northcott \\ Department of Sociology \\ University of Alberta \\ Edmonton, Alberta, Canada \\ E-mail: herb.northcott@ualberta.ca
}

This collection of 12 papers along with an introduction by the editors examines the impact of population aging (the increase in the mean age of the population together with the increase in the percentage of the population which is elderly) on economic productivity. These 12 papers were originally presented at a symposium in December 2004 co-sponsored by the European Union and the Vienna Institute of Demography and were published in March of 2008 as a Supplement to Volume 34 of the Population and Development Review.

The demographic transition, a function of declining fertility and increasing life expectancy, has proceeded at different rates and to different degrees in the various countries of the world. Initially, the demographic transition tends to be accompanied by high rates of population growth which are subsequently followed by declining growth rates coupled with population aging. Economists have been interested in the economic consequences of these demographic shifts from high to low rates of population growth and from a preponderantly youthful population to a population with a higher median age and higher percentages of older people. When the labour force is growing faster than the total population, as is the case early in the demographic transition or in the case of a youthful "baby boom", a demographic dividend tends to be realized depending on a country's social policies, culture, and economic environment. With population aging, this demographic dividend can become a demographic burden in the situation where the labour force is growing at a slower rate than the total population. 
The aging of populations world wide may prove to be one of the dominate features of the twenty-first century and is a phenomenon that is unprecedented in human history. As such, it is not clear what economic consequences will result or how countries should respond to best manage this demographic shift and its economic consequences. Ironically, while rapid population growth has been considered an economic disadvantage, low or negative growth accompanied by population aging is also often thought to be economically disadvantaging. One of the central issues concerns the declining relative size and increasing age of the labour force. Questions are raised about the ratio of non-workers to workers (the so-called dependency ratio), the sustainability of social programs such as health care and income support mechanisms for retirees, and the substitutability of older workers for younger workers. This last point raises questions about the productivity of younger versus older workers. While younger workers have the advantage of often better health and vitality as well as the advantage of being recently educated and trained, older workers have the advantage of experience, have developed interpersonal skills, and may make better managers. Older and younger workers tend to bring different human capital to the labour market, and may have different productivity profiles, and different patterns of savings and consumption. These profiles of younger and older workers and the economic consequences of an older work force may depend on a number of social and labour market characteristics, policies and practices. For example, rapid technological change may disadvantage older workers and disadvantage companies and countries with an aging work force. On the other hand, investments in on-going education for both older and younger workers may facilitate adjustment to rapid technological change. As another example, the trend toward a shrinking and aging labour force may be ameliorated by eliminating mandatory retirement policies and instituting policies which encourage older workers to remain in the labour force.

The economic consequences of an aging population require analyses at the level of the individual, firm, and country, and vary from country to country and time to time depending on social and economic policies. This book suggests that some countries have institutional environments that may exacerbate the problems of population aging while other countries have policy environments that may facilitate adjustment to changing age structures in ways that encourage economic productivity and growth.

Population aging is often thought to have negative consequences economically for two reasons: one, the increasing ratio of non-workers to workers is associated with declines in productivity per capita, and two, the increasing age of workers is associated with declines in productivity per worker. However, the productivity of workers may depend on social and economic contexts as much or more than on the age of workers. The editors of this book suggest that there are both positive and negative views of the effects of 
population aging on economic productivity. The positive view argues that appropriate social and economic policies can respond to population aging with the result that economic productivity will be not be negatively impacted. The negative view argues that countries and labour markets may not be able to adjust effectively to population aging and that this trend will have negative consequences economically.

This book is described on its cover as economic demography. The papers vary in their emphasis, and include variable amounts of psychology, sociology, and policy analysis. Nevertheless, the primary character of these chapters is economic and the reader requires a good deal of insight and competence into economic theory and methods in order to be comfortable with this work. As a sociologist with an interest in population aging, I found that my lack of training in economics made this a difficult read at times. Nevertheless, I came away with an appreciation of the complexity of the "problem" of population aging and was impressed that there is no clear or easy agreement on the economic advantages and disadvantages of population aging or on appropriate social and economic policy responses. As the editors observe in their introduction to this book: “... almost all of the contributions to this volume stress the importance of institutional settings for translating the effects of changing age structure and human capital into productivity" (page 13). In short, while the demographic transition resulting in population aging is becoming a world-wide phenomenon, the economic consequences of this transition are not inevitable and will depend on how societies adjust their social policies and programs, their cultural norms, and their economic institutions to respond to the population aging trend. 